\title{
UPAYA MASYARAKAT LOKAL DALAM MENJAGA KEAMANAN DAN KENYAMANAN WISATAWAN DI DESA ADAT UBUD (Studi Tindakan Sosial dalam Pariwisata)
}

\author{
I Wayan Cahya Suputera a, 1, I Gst. Agung Oka Mahagangga a,2 \\ 1 cahyaputera8@gmail.com, ${ }^{2}$ ragalanka@gmail.com \\ a Program Studi S1 Destinasi Pariwisata,Fakultas Pariwisata,Universitas Udayana, Jl. Dr. R. Goris, Denpasar, Bali 80232 Indonesia
}

\section{ABSTRACT}

Ubud traditional village is a tourist area which is located in Gianyar regency. If the tourist want know the culture of Bali they must come to Ubud. However, many issues and problems arise associated with security and tourists comfortness. Based on it, this research was conducted to analyze the Local Community Efforts in Maintaining Security and Tourists Comfortness in Ubud Traditional Village.The method used in this research is a research method with qualitative descriptive analysis technique to analyze the efforts and actions of local communities. Sources of data derived from primary data and secondary data. Data collecting technique using in-depth interviews, observation and study of literatures. Determination of informants from local communities in this study using purposive sampling technique. This study is limited by the analysis of the social action theories and coordination systems. The results of this research obtained that local community efforts in maintaining security is the assignment of trepti unit who participate in keeping any tourism activities..

Keywords: Social Actions of Communities, Trepti, Security and Comfortness, Ubud Traditional Village

\section{PENDAHULUAN}

Pariwisata merupakan sebuah industri yang mempunyai prospek yang sangat menjanjikan di masa depan. Kegiatan pariwiata tidak mengenal ruang dan waktu untuk dilaksanakan. Perkembangan pariwisata yang begitu cepat seringkali tidak diikuti dengan pola pikir masyarakat terhadap dampakdampak sosial yang akan terjadi di sebuah kawasan yang dijadikan sebagai destinasi pariwisata.

Desa Adat Ubud adalah sebuah kawasan pariwisata yang dikenal sejak tahun 1930an dengan mengedepankan konsep desa wisata. Suasana Desa Adat Ubud dengan seluruh isinya adalah potensi besar yang sempurna dengan menyatukan tradisi dan budaya yang merupakan karakter kuat dari masyarakat Desa Adat Ubud. (Nurjaya, 2011)

Namun apa daya perkembangan industri pariwisata yang terlalu cepat memicu terjadinya kekhawatiran dari masyarakat lokal terhadap situasi keamanan dan kenyamanan wisatawan maupun masyarakat lokal itu sendiri. Hal ini dikarenakan mulai berdatangan penduduk pendatang yang ingin mencari pekerjaan dalam sektor pariwisata seperti bekerja di hotel, villa, restoran, pasar dan ada juga yang menjalani profesi sebagai pedagang acung.
Mengacu terhadap pengaduan gangguan keamanan dan kenyamanan yang menimpa wisatawan di kawasan pariwisata, bermunculan ekspatriat yang mengatas namakan komunitasnya sebagai orang-orang yang perduli terhadap perkembangan keamanan dan kenyamanan pariwisata di Ubud. Salah satu komunitas yang dibentuk adalah Ubud Watch, Ubud Watch merupakan sebuah akun sosial media yang dapat diakses oleh siapa saja yang telah mengalami gangguan keamanan dan kenyamanan di kawasan pariwisata khususnya Ubud.

Ubud Watch adalah sebuah situs web dengan membuat pemetaan yang menunjukan lokasi terjadinya tindakan yang dialami oleh wisatawan seperti: pencurian, pelecehan seksual, kebersihan lingkungan. Laporan pengaduan keamanan dan kenyamanan yang tersimpan dalam Situs web Ubud Watch mulai terjadi pada tahun 2012 sampai tahun 2015 . Tujuan ekspatriat membentuk Situs Ubud Watch adalah memudahkan dalam mencari bantuan dari banjar dan polisi untuk mengatasi permasalahan keamanan dan kenyamanan yang menimpa wisatawan. Dalam laporan Ubud Watch terjadi 54 kasus pengaduan di Wilayah Ubud pada tahun 2014 (https://ubudwatch.org/)

Kasus-kasus yang menimpa orang asing atau wisatawan tentunya menjadi perhatian 
khusus agar dapat diselesaikan permasalahanya. Melihat dari pertumbuhan kasus yang menimpa orang asing atau wisatawan dalam laporan Polda Bali sebagai berikut;

Tabel 1

Data Orang Asing/ Wisatawan yang Menjadi Korban Kriminalitas di Bali

\begin{tabular}{|c|l|c|c|}
\hline No & Tahun & $\begin{array}{c}\text { Jumlah } \\
\text { Korban }\end{array}$ & $\begin{array}{c}\text { Pertumuha } \\
\text { n (\%) }\end{array}$ \\
\hline 1 & 2011 & 219 orang & $28.81 \%$ \\
\hline 2 & 2012 & 134 orang & $17.63 \%$ \\
\hline 3 & 2013 & 217 orang & $28.55 \%$ \\
\hline 4 & 2014 & 190 orang & $25 \%$ \\
\hline \multicolumn{2}{|c|}{ Total } & $\mathbf{7 6 0}$ orang & $\mathbf{1 0 0 \%}$ \\
\hline
\end{tabular}

Sumber: Polda Bali, 2015

Berdasarkan tabel 1 pada tahun 2011 orang asing yang mengalami gangguan keamanan tercatat 219 orang, dan tahun 2012 terjadi penurunan menjadi 134 orang tetapi pada tahun 2013 mengalami peningkatan menjadi 217 orang asing yang mengalami gangguan keamanan. Ini menunjukan terjadinya fluktuasi tingkat keamanan yang mengganggu orang asing atau wisatawan. Semestinya Provinsi Bali yang mengandalkan sektor pariwisata mampu terus menekan angka kriminalitas yang menimpa orang asing. Penekanan terhadap ancaman keamanan dan kenyamanan tidak hanya menjadi tugas pihak berwajib, tetapi membutuhkan tindakan dan koordinasi masyarakat lokal dengan pihak kepolisian dan institusi kepemerintahan.

Berdasarkan hal tersebut, perlu dilakukan kajian mengenai upaya masyarakat lokal dalam menjaga keamanan dan kenyamanan wisatawan di Desa Adat Ubud karena wisatawan yang berkunjung lebih melakukan interaksi terhadap aktivitas dan tradisi masyarakat lokal.

Tulisan ini diharapkan dapat memberikan hasil berupa upaya masyarakat lokal di Desa Adat Ubud dalam memberikan pelayanan keamanan dan kenyamanan kepada wisatawan, dimana hal tersebut sangat berguna bagi daerah-daerah yang mengandalkan Desa adat sebagai kawasan pariwisata. Selain itu penelitian ini dapat memberikan manfaat secara akademis kepada mahasiswa.

\section{SITUASI KEAMANAN DAN KENYAMANAN DI DESA ADAT UBUD}

Desa Adat Ubud sebagai sentral dari kunjungan wisatawan memerlukan pemetaan keamanan yang nantinya dapat mencegah tindak kriminalitas terhadap wisatawan. Polsek Ubud menetapkan sebuah pemetaan khusus yang menyebutkan bahwa di Kelurahan Ubud termasuk Desa Adat Ubud didalamnya merupakan titik kerawanan keamanan dan kenyamanan gambar1.

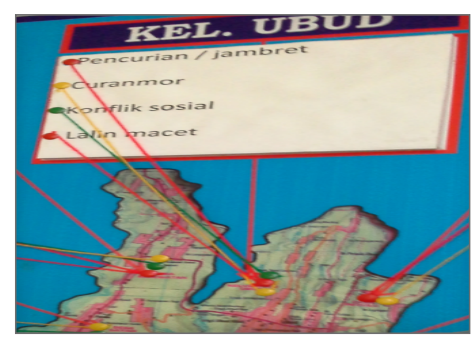

Gambar 1

Pemetaan Ancaman Keamanan dan Kenyamanan di Kelurahan Ubud

Sumber: Polsek Ubud, 2015

Pemetaan gambar 1 menunjukan ada tiga warna garis yang berbeda yaitu warna merah, hijau dan kuning. Garis yang berwarna merah adalah zona rawan terjadinya pencurian, konflik sosial dan kemacetan. Desa Adat Ubud termasuk dalam katagori garis yang berwarna merah, ini terjadi karena arus dari kegiatan pariwisata terpusat di Desa adat Ubud.

Keamanan yang terorganisir di lingkungan Desa Adat Ubud menjadi usaha dalam pencegahan tindakan pidana yang menimpa wisatawan. Ditinjau dari laporan Polres Gianyar menyangkut permasalahan keamanan yang menimpa wisatawan dapat dilihat dalam tabel 2 .

Tabel 2

Wisatawan Yang Menjadi Korban Tindakan Kriminal

Di Kabupaten Gianyar

\begin{tabular}{|c|c|c|l|}
\hline No & Tahun & $\begin{array}{c}\text { Jumlah } \\
\text { Korban }\end{array}$ & \multicolumn{1}{|c|}{ Jenis Kasus } \\
\hline 1 & 2011 & 26 & $\begin{array}{l}\text { Kecelakaan lalu lintas, } \\
\text { penjambretan, } \\
\text { pencurian, pemalsuan } \\
\text { dokumen }\end{array}$ \\
\hline 2 & 2012 & 16 & $\begin{array}{l}\text { Pencurian, penganiayaan, } \\
\text { penipuan \& pengelapan, } \\
\text { penjambretan, } \\
\text { kecelakaan lalu lintas }\end{array}$ \\
\hline 3 & 2013 & 18 & $\begin{array}{l}\text { Pencurian, kecelakaan } \\
\text { lalu lintas }\end{array}$ \\
\hline
\end{tabular}


Vol. 4 No 2, 2016

\begin{tabular}{|c|c|c|l|}
\hline 4 & 2014 & 6 & $\begin{array}{l}\text { Pencurian, kecelakaan } \\
\text { lalu lintas dan } \\
\text { pembunuhan. }\end{array}$ \\
\hline \multicolumn{2}{|c|}{ Total } & 66 & \\
\hline
\end{tabular}

Sumber: Polda Bali, 2015

Dalam tabel 2 menunjukkan bahwa gangguan keamanan yang terjadi kepada wisatawan dalam empat tahun terakhir di lingkungan Polres Gianyar mengalami penurunan. Gangguan keamanan yang terus muncul setiap tahun adalah pencurian yang didominasi di lingkungan pariwisata Kabupaten Gianyar. Pencurian yang menimpa wisatawan di lingkungan desa adat yang menjadi basis pariwisata menjadi pembuktian bahwa keamanan masih perlu ditingkatkan.

Laporan yang diterima oleh pihak kepolisian dari wisatawan yang tercatat ke dalam tindakan kriminal berdasarkan penyidikan yang merupakan sebuah perkara pidana yang telah diproses secara hukum. Namun, beberapa laporan yang masuk ke kepolisian dan setelah dilakukan penyelidikan, laporan yang dikeluhkan oleh wisatawan ternyata bukan merupakan tindakan kriminal melainkan kelalaian dari wisatawan tersebut.

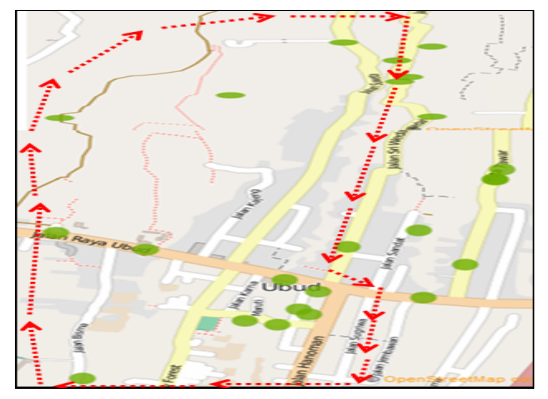

Gambar 2

Laporan Tindakan Kriminal dalam Situs Ubud Watch

Sumber: Ubud Watch, 2015

Gambar 2 menunjukan laporan yang diunggah ke dalam situs web Ubud Watch. Desa Adat Ubud berada di dalam garis putus- putus yang berwarna merah. Titik-titik yang berwarna hijau yang berada dalam garis merah merupakan tempat dimana wisatawan mengalami tindakan yang tidak menyenangkan menyangkut keamanan dan kenyamanan.

Penelitian mengenai keamanan dan kenyamanan sebelumnya pernah dilakukan oleh Mahagangga.dkk, (2013). Hasil dari penelitian tersebut adalah keamanan dan kenyamanan wisatawan tidak hanya dapat diselesaikan dengan kecanggihan teknologi, sistem yang berstandar internasional atau efektifitas secara partial dari salah satu komponen, melainkan peran serta dari bawah, utamanya upaya masyarakat yang berhadapan langsung dengan wisatawan.

\section{METODE PENELITIAN}

Lokasi penelitian ini dilakukan di Desa Adat Ubud yang terfokus di lingkungan Banjar Adat Ubud Kelod, Lokasi tersebut dipilih karena menjadi titik sentral pesatnya pertumbuhan pariwisata di Ubud.

Upaya masyarakat lokal yang dimaksud dalam artikel ini adalah bagaimanan tindakan sosial dalam lingkungan desa adat untuk memberikan pelayanan keamanan dan kenyamanan kepada wisatawan yang berada di lingkungan Desa Adat Ubud.

Metode pengumpulan data yang dilakukan dengan cara melakukan pengamatan, wawancara dan studi kepustakaan. Pengamatan dilakukan untuk mengetahui situasi secara langsung keadaan di lapangan. Wawancara dilakukan dengan masing-masing tokoh adat yang berada di lingkungan Desa Adat Ubud. Sedangakan studi kepustakaan digunakan untuk mencari data yang berkaitan dengan penelitian. Dalam penelitan ini literatur yang dicari berupa dokumen seperti gangguan keamanan dan kenyaman wisatawan di Kabupaten Gianar Provinsi Bali.

Penentuan informan menggunakan teknik purposive sampling yaitu informan sebagai sumber data dengan pertimbangan tertentu, karena orang tersebut dianggap paling tahu tentang apa yang kita harapkan sehingga akan memudahkan peneliti menjelajahi objek atau situasi sosial yang diteliti. (Sugiyono, 2014)

Teknik analisis data dalam penelitian kualitatif dilakukan sebelum memasuki lapangan, selama di lapangan, dan setelah selesai di lapangan. Analisis telah dimulai sejak merumuskan dan menjelaskan masalah, sebelum terjun ke lapangan dan berlangsung terus sampai penulisan hasil penelitian Nasution dalam (Sugiyono, 2014). Dalam penelitian ini menggunakan tiga langkah dalam proses analisis data yaitu reduksi data, penyajian data, dan menarik kesimpulan Miles dan Huberman dalam (Sugiyono, 2014). 
IV. UPAYA MASYARKAT LOKAL DALAM MENJAGA KEAMANAN DAN KENYAMANAN WISATAWAN DI DESA ADAT UBUD

Upaya yang dilakukan dalam menjaga kemananan dan kenyamanan di lingkungan Desa Adat Ubud mengacu kepada teori tindakan sosial sebagai analis. Max Weber (dalam Ritzer, 1992) membedakan tindakan sosial kedalam empat kategori sebagai berikut :

1. Zwerk Rational (Rasionalitas Instrumental) adalah tindakan yang dilaksanakan setelah melakukan pertimbangan matang mengenai tujuan dan cara yang akan ditempuh untuk meraih tujuan itu, Zwerk Rational melekat pada tindakan yang diarahkan secara rasional untuk mencapai satu tujuan tertentu.

2. Werk Rational (Rasionalitas Nilai) tindakan-tindakan sosial ditentukan oleh pertimbangan-pertimbangan atas dasar keyakinan individu pada nilai-nilai etetis, etis, dan keagamaan.

3. Affectual Action (Tindakan yang dipengaruhi Emosi) tindakan sosial ini dipengaruhi oleh emosi dan perasaan seseorang kepada orang lain.

4. Traditional Action (Tindakan karena Kebiasaan) tindakan sosial ini dilakukan semata-mata mengikuti tradisi atau kebiasaan yang sudah baku.

Desa Adat Ubud membuktikan bahwa pariwisata dibangun berdasarkan nilai-nilai adat dan kebudayaan masyarakat lokal, bukan pariwisata yang menciptakan kebuadayaan. Kunjungan wistawan terus mengalami peningkatan, tidak heran masyarakat mengadakan sebuah upaya untuk membentuk satuan keamanan adat.

Musyawarah kemudian dilaksanakan oleh Desa Adat Ubud untuk membahas permasalah keamanan dan kenyamnan yang dihadiri oleh: Kepala Dinas Ubud Kelod, Bendesa Adat Ubud, Kelian Adat Ubud Kelod, Kepala Lingkungan Ubud Kelod, dan Lurah Ubud.

Musyawarah yang dilaksanakan atas dasar sebagai berikut;

1. Semakin majunya kehidupan pariwisata di Desa adat Ubud maka perlu setiap warga menjaga ketertiban dan keamanan di lingkungan Desa Adat Ubud

2. Dalam mengatur aspek-aspek kehidupan ditujukan untuk menciptakan kesukertaan (tertib, aman, damai) dalam kehidupan Desa Adat Ubud yang harmonis

3. Awig-awig merupakan hukum dasar dalam mengatur kehidupan lembaga-lembaga adat yang ada, maka awig-awig hanya memuat hal-hal yang pokok, sedangkan hal-hal yang memerlukan penjelasan lebih rinci diatur dalam perareman lepas

Hasil dari pada musyawarah yang telah dilaksanakan di Banjar Ubud Kelod adalah terbentuknya satuan keamanan yang disebut dengan Trepti.

"Tujuan saya menggagas dibentuknya trepti karena melihat perkembangan pariwisata dapat mengancam keamanan dan kenyamanan di lingkungan Ubud kelod, secara kuantitas di lingkungan Ubud kelod mempunyai wilayah yang lebih luas dengan jumlah sarana pariwisata yang lebih padat".

Berdasarkan penuturan dengan bapak I Nyoman Yoga selaku kelian banjar adat Ubud Kelod yang menjadi penggagas dibentuknya trepti menyatakan bahwa tujuanya adalah perkembangan pariwisata yang tidak disiplin dapat mengancam keamanan dan kenyamanan yang berimbas kepada wisatawan maupun masyarakat lokal.

Dibentuknya satuan keamanan dan kenyamanan trepti juga mempunyai dasar kuat yang mengacu kepada:

1. Undang -Undang Dasar Tahun 1945

2. Peraturan Pemerintah tentang ketertiban umun

3. Perda no 12 tahun 1992 tentang kebersihan dan ketertiban umum

4. Keputusan Lurah Ubud No:01/901/Pem/1994 tentang kebersihan dan keamanan umum

5. Awig-awig Desa Pakraman desa Pakraman Ubud tentang palemahan (alam) dan pawongan (manusia)

6. Parareman (peraturan) tentang krama tamiu (penduduk pendatang) pawongan (manusia) dan palemahan (alam)

7. Hasil Paruman banjar (musyawarah) hari sabtu, 28 Agustus 2010.

Tindakan sosial yang dilakukan oleh masyarakat Desa Adat Ubud terkait dengan pembentukan anggota trepti, sesuai dengan teori tindakan sosial yang dapat dikategorikan sebagai tindakan zwerk rational (rasionalitas instrumental) karena berdasarkan UUD 1945, 
Peraturan Pemerintah tentang ketertiban umum, mengacu kepada Perda dan berdasarkan keputusan Lurah Ubud. Selain itu, juga dikategorikan sebagai werk rational (rasionalitas nilai) karena trepti dibentuk berdasarkan awig-awig, perareman, dan hasil paruman banjar (musyawarah) yang mempunyai nilai hukum adat yang tinggi dan dihormati masyarkat lokal.

Dengan dibentuknya satuan keamanan dan kenyamanan trepti, harus memperoleh dukungan dari pihak kepolisian dan instansi terkait seperti; Polsek Ubud dan Kelurahan Ubud. Karena akan terjalin koordinasi yang kondusif dengan organisasi adat.

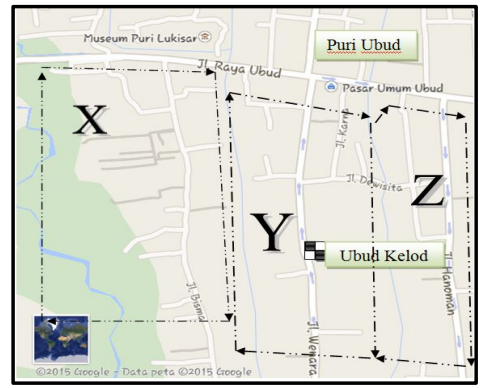

Gambar 3

Pemetaan Wilayah Trepti di Banjar Adat Ubud Kelod

Sumber: Hasil Penelitian 2015

Gambar 3 menunjukan tiga lokasi pemetaan zona trepti, zona (x) kawasan Junggut, zona (y) kawasan Babakan dan zona (z) kawasan Kelod Kangin. Anggota trepti bersal dari masing-masing warga dari ketiga zona tersebut. Sampai saat ini jumlah anggota trepti sebanyak duapuluh delapan orang.

Trepti bertugas di lingkungan Banjar Ubud Kelod dengan pembagian waktu 24 jam. Masing-masing anggota akan melakukan pertukaran tugas sesuai dengan waktu yang telah ditentukan. Trepti bertugas sesuai dengan koordinasi dari ketua trepti. Tujuannya adalah agar tidak terjadinya tindakan yang menimbulkan benturan fisik.

Contohnya upaya trepti didalam menertibkan kegiatan live music. Kegiatan live music yang terjadi dilingkungan Banjar Ubud Kelod sebenarnya telah diberikan batasa waktu hingga pukul 23.00 wita, tatapi seringkali pihak penyelenggara melupakan aturan tersebut sehingga mendatkan laporan dari desa-desa tetangga, masyarakat, dan pemilik villa yang menyatakan kenyamanannya terganggu.

Kemudian untuk mengatasi permasalah tersebut koordinator Trepti menugaskan anggotanya untuk meminta tanda tangan kepada yang melaporakan keluhan kenyamanan. Setelah beberapa tanda tangan terkumpul koordinator akan menuju dimana tempat live music itu diadakan dan menunjukan bukti tanda tanggan dari warga maupun wistawan bahwa kenyamanan mereka terganggu karena kegitan live music.

Anggota trepti yang bertugas pada malam hari selain menertibkan kegiatan live music, juga akan mencegah niat-niat jahat dari pelaku tindak kriminal yang melakukan aksi di lingkungan desa wisata. Kasus-kasus yang terjadi seperti penjambretan dan pencurian barang-barang milik wisatawan seperti yang terdapat dalam tabel 2.

Keberadaan anggota satuan keamanana dan kenyaman trepti di lingkungan pariwisata telah membuktikan bahawa desa adat sebagai tempat yang menerima retribusi tidak hanya menerima keuntungan saja tetapi mampu membentuk satuan keamananan dan kenyamanan dengan basis dan aturan adat yang berlaku.

\section{PENUTUP \\ Simpulan}

Berdasarkan tulisan diatas, upaya masyarkat lokal dalam menjaga keamanan dan kenyamanan wisatawan dapat dikatagorikan sebagai tindakan sosial zwerk rational (rasionalitas instrumental) dan tindakan werk rational (rasionalitas nilai) karena telah berhasil membentuk satuan keamanan yang disebut dengan trepti atas dasar hukum UUD 1945 dan awig-awig Adat Ubud. Jumlah anggota trepti dua puluh delapan orang dan berasal dari tiga kawasan di Banjar Ubud Kelod yaitu kawasan junggut, kawasan babakan dan kawasan kelod kangin. Dengan dibentuknya satuan keamanan dan kenyamanan trepti masyarakat memberikan harapan yang besar terhadap situasi keamanan di daerah yang mengandalkan sektor industri pariwisata.

\section{Saran}

Anggota trepti semestinya memperhatikan pengaduan masalah keamanan dan kenyamanan dari laporan-laporan yang menimpa wisatawan di dalam media sosial 
khususnya yang terjadi di Ubud. Sebaiknya anggoata trepti berasal dan bertugas di keempat lingkungan Banjar Adat di Desa Adat Ubud karena industri pariwisata di Desa Adat Ubud sudah mengalami perkembangan secara merata dan membutuhkan pengamanan yang sama seperti di Banjar Ubud Kelod. Diharapkan

\section{Daftar Pustaka}

Nurjaya, I Wayan. 2011. Persepsi Wisatawan Mancanegara Terhadap Potensi Pariwisata di Kelurahan Desa adat Ubud, Kabupaten Gianyar.Tesis, Pasca Sarjana: Universitas Udayana

Mahagangga, I Gst. Ag. Oka. Dkk. 2013. Keamanan dan Kenyamanan Wisatawan di Bali (Kajian Awal Kriminalitas Pariwisata). Jurnal analisis Pariwisata vol. 13.(01). Denpasar: Fakultas Pariwisata Universitas Udayana

Sugiyono. 2014. Metode Penelitian Kuantitatif Kualitatif dan R\&D. Bandung : Penerbit Alfabeta

Ritzer, George.1992. Sosiologi Ilmu Pengetahuan Berparadigma Ganda. Terjemahan Alimandan. Jakarta :Rajawali

Sumber web :

https://ubudwatch.org/ anggota trepti tidak melakukan kekerasan fisik secara langsung ketika bertugas menjaga keamanan dan kenyamanan di Desa Adat Ubud. 